\title{
“O Combate Naval do Riachuelo" (1883) como leilão: o Salão Caricatural da Revista Illustrada (1876-1898) e a crítica à pintura histórica
}

\author{
Sabrina Medeiros ${ }^{1}$ \\ DOI 10.20396/eha.vil4.3434
}

Minha fala deriva dos resultados e reflexões em torno da Iniciação Científica que realizo desde 2018. Antes de tudo, gostaria de ressaltar como minha pesquisa parte de uma fonte específica, quase como um estudo de caso. No entanto, esse estudo leva em conta dimensões que excedem a ideia de que o caso em questão seja isolado ou restrito em si mesmo. Assim, parto de um objeto específico para então me referir a questões que se relacionam com o seu contexto cultural de maneira mais ampla.

Dito isto, sigo com a fonte em questão. Trata-se de uma caricatura (Figura 1) apresentada no número 363 da Revista Illustrada, periódico que circulou no Rio de Janeiro do século XIX. As caricaturas apresentadas no periódico, boa parte delas produzidas por Angelo Agostini, são constantemente objetos de análise de diferentes enfoques e problematizações, desde a questão abolicionista até a crítica de arte.

Nesse sentido, destaca-se a figura de Angelo Agostini, dono da Revista Illustrada e principal responsável pelas suas ilustrações. Agostini é outra figura bastante citada pela historiografia da imprensa, e aparece também em trabalhos referentes ao movimento abolicionista e ao republicanismo. Teve uma profícua carreira na imprensa do oitocentos, atuando em diferentes periódicos como o Diabo Coxo, O Cabrião, A Vida Fluminense, O Mosquito e, por fim, a Revista Illustrada-, sobretudo como ilustrador. ${ }^{2}$

Apresentados o produtor da caricatura e o seu veículo de circulação, voltemos à fonte em si. Produzida como uma crítica ilustrada, uma maneira de satirizar os elementos passíveis de crítica

\footnotetext{
1 Esta publicação faz parte da pesquisa de desenvolvida na graduação intitulada "O Combate Naval do Riachuelo' (1883) como leilão: o Salão Caricatural da Revista Illustrada e a crítica à pintura histórica", orientada pela Profa. Dra. Letícia Coelho Squeff, desenvolvida no Departamento de História da Arte da Universidade Federal de São Paulo. A pesquisa conta com financiamento da Fundação de Amparo à Pesquisa do Estado de São Paulo - FAPESP, sob o n. ${ }^{\circ}$ processual 2017/26962-4.

2 Sobre essas produções, vale citar algumas de maior destaque, como a de Marcelo Balaban, Gilberto Maringoni Oliveira, José Carlos Augusto. (Cf. AUCUSTO, José Carlos. Um provinciano na corte: as aventuras de "Nhom-Quim" e a sociedade do Rio de Janeiro nos anos 1860-1870. Dissertação (Mestrado em História). 2008. FFLCH-USP, São Paulo; BALABAN, Marcelo. Poeta do lápis: sátira e política na trajetória de Angelo Agostini no Brasil Imperial (1864-1888). Campinas, SP: Editora da Unicamp, 2009; MARINGONI, Gilberto. Angelo Agostini: A Imprensa Illustrada da Corte à Capital Federal: 1864-1910. São Paulo: Devir Livraria, 2011.)
} 
em um quadro a partir de uma composição visual, a caricatura analisada é uma reprodução crítica de O Combate Naval do Riachuelo, quadro de batalha de Vítor Meireles. É importante observar como a caricatura realmente se atém à fidelidade da composição original, subvertendo seu sentido a partir de pequenos detalhes, que adquirem ainda mais sentido quando observados em conjunto com a legenda. Além disso, é importante também notar como a caricatura não está isolada na página, mas é acompanhada por duas colunas de texto e uma sequência narrativa ilustrada. Retomarei esses elementos mais pra frente.

Ao longo da pesquisa, segui a ideia de que a caricatura ressignifica a obra em questão através da interpretação posta no âmbito do visual. Nesse sentido, foi importante na pesquisa as ideias apresentadas por Michael Baxandall ${ }^{3}$ em seu livro Padrões de Intenção. Baxandall explora a intepretação de fontes visuais, sobretudo de obras de arte, como tarefas vinculadas intrinsecamente a subjetividade do observador, considerando o ato de "ver" como um processo extremamente único e com suas particularidades. A seleção de um caminho para a descrição depende muito do observador. A leitura da descrição, por sua vez, pode ser considerada como um outro processo subjetivo que parte do leitor, no qual os aspectos destacados na descrição passam a ter maior relevância e destaque na observação de uma obra de arte - é fornecida ao leitor uma nova maneira de olhar para o quadro, com novas referências visuais fornecidas pela caricatura. Assim, a metodologia da pesquisa, inserida entre a História cultural e a análise visual, seguiu o caminho da compreensão dos discursos que compõem essa interpretação do quadro pelo periódico, levando em conta os novos sentidos que apresenta aos leitores sobre a obra em questão.

Trata-se de um leilão. A legenda cria uma nova narrativa para a cena que se desenvolve na composição - e vale ressaltar como a narrativa é um elemento fundamental para a apresentação da pintura histórica, que sempre vinha acompanhada nas Exposições Gerais de Bellas Artes de uma explicação histórica e da narrativa da cena apresentada. Na Revista Illustrada, o combate não é mais um combate. O chefe da embarcação brasileira, que originalmente estaria acenando a vitória em batalha, agora é simplesmente aquele que leiloa quinquilharias, como destroços das embarcações paraguaias. Os paraguaios, em sua posição, estão alheios à cena: fumando, dormindo, pescando, não percebem os brasileiros como um perigo - até porque, pela legenda da caricatura, não o são. Com os detalhes apresentados na imagem, a caricatura complementa a legenda e vice-versa, subvertendo completamente o objetivo da composição - o de criar uma cena idealizada que repre-

3 BAXANDALL, Michael. Padrões de intenção: a explicação histórica dos quadros. São Paulo: Companhia das Letras, 2006. 
sentasse um episódio histórico nacional. De heróis, os brasileiros passam a fanfarrões. De combatentes, os paraguaios se transformam em personagens passivos. Esse tipo de crítica não somente aponta os supostos defeitos da pintura, mas vai além, criando uma nova identidade visual para a composição. Citando a legenda:

Descripção do quadro: Offendidos os brios e a dignidade do Brazil pela guerra que sem motivo, etc, etc, etc... Isto é o que diz o catalogo, porem como não há ninguém que não saiba disso, deixemos essa serra patriótica, e olhemos para o quadro do Sr Victor Meirelles. No passadiço do "Amazonas" estão quatro officiaes gigantescos, entre os quaes se distingue o ainda mais gigantesco chefe Barroso, que grita: Tenho $20 \# 000$ rs. pelo casco! 25, 30. Trinta mil reis tenhos meus Srs. Trinta, trintaaa! [...]. No primeiro plano do quadro está o tal casco em questão, sobre ele alguns paraguayos indiferentes ao que se passa, entregamse as doçuras da pescaria e outros as da bisca ou do pacau.

Os detalhes caricaturados e apresentados na legenda se relacionam diretamente com a crítica escrita apresentada pelo periódico - diferencio aqui porque o periódico apresenta, de fato, uma crítica que propõe maior "seriedade", por assim dizer, e outra que é ilustrada e caricaturiza os quadros. Dois pontos são cruciais na crítica ao quadro de Meireles, nesse sentido: a proporcionalidade e a representação do grupo dos paraguaios. Nesse caso, são justamente esses os dois elementos caricaturados pela Revista. O almirante Barroso, se olharmos melhor, possui o tamanho quase igual da embarcação, o grupo dos paraguaios, por sua vez, alvo de críticas por sua suposta "falta de ação", são representados de maneira passiva.

Agora que está apresentada a ideia principal, então, sigo com alguns elementos que considero importantes na construção desse discurso apresentado pela crítica de arte feita através da caricatura. Em primeiro lugar, é preciso ressaltar como esse tipo de crítica era muito comum na França, os chamados de Salões caricaturais ou salão para rir. É um tipo de crítica que reproduz obras expostas nos Salons e se utiliza da sátira e da caricatura como maneira de apontar os elementos criticados. ${ }^{4}$ Os salões caricaturais alcançaram grande sucesso na França, de onde Angelo Agostini provavelmente retirou sua inspiração para os salões que apresenta na Revista Illustrada e n'O Mosquito, dos quais faz parte a caricatura do Riachuelo.

A comparação entre os salões caricaturais franceses e os de Agostini fazem parte da próxima etapa da pesquisa, tópico sobre o qual ainda não tenho, portanto, conclusões. Ainda assim, gosta-

4 A tese de Rosângela de Jesus Silva apresenta um panorama bastante rico sobre a produção ilustrada de Agostini, abordando também os salões caricaturais franceses e sua possível - até provável - conexão com o ilustrador ítalo-brasileiro. (Cf. SILVA, Rosângela de Jesus. O Brasil de Angelo Agostini: política e sociedade nas imagens de um artista. Tese (Doutorado em História). 2010. IFCH-UNICAMP, Campinas-SP.) 
ria de apontar um elemento que considero bastante importante nas análises preliminares já realizadas. O principal deles é o sentido do didatismo, da ideia de que as caricaturas ali apresentadas devem servir de ensino para a população, uma maneira de lhes educar o olhar. ${ }^{5}$ Observei muitos salões caricaturais franceses que apresentavam a reação do público às obras como argumento para sua crítica. Assim, o público se tornava o principal vetor da crítica caricatural, expressando claramente as reações diante dos quadros. Se os salões se apoiavam de fato em reações do público e lhe exageravam ou se essa reação apresentada na caricatura era totalmente construída, de maneira a construir um argumento convincente da crítica, não sei afirmar. Mas é fato que o público era um elemento importante. Esse tipo de salão, no entanto, é muito mais raro nas produções de Agostini. Seus salões tendem a apresentar as reproduções dos quadros sem a apresentação de um cenário ou de personagens que interajam com eles. Rosângela de Jesus Silva, que apresentou uma tese sobre a produção artística de Agostini, relaciona seus salões caricaturais e a maneira como os apresenta a um discurso didático do periódico. Eu concordo com esse argumento. Alguns pesquisadores que tiveram Agostini como objeto de estudo destacam o discurso didático que movia muitos dos periódicos onde trabalhou, incluindo a Revista Illustrada. É a ideia de que as caricaturas ali apresentadas serviriam como um buril ao gosto da população, que aprenderia a apreciar melhor as obras de arte. Nesse sentido, as caricaturas buscam apresentar ao leitor os defeitos da obra de maneira cômica, sempre buscando que o leitor compreenda e "veja", por si mesmo, esses erros.

Alguns outros elementos são incorporados também na construção do discurso crítico do periódico, e esses também possuem relação direta com os salões caricaturais. Na retórica de Agostini e da Revista Illustrada, é comum observar termos como "verdade", "verdade histórica", crítica "justa" e "progresso".

O ideal de verdade ou de uma critica "justa” normalmente se relacionava a afirmação de uma certa isenção da Revista Illustrada diante do cenário em que se encontrava. Segundo as críticas que apresentou sobre o Riachuelo, sua intenção nunca é a ofensa, senão apresentar as verdades, incômodas ou não, sobre a obra. Esse discurso permeia todas as publicações, não somente os ê comentários relacionados à arte. O crítico, portanto, não apresenta uma visão sobre o quadro, mas apresenta uma crítica que seria verdadeira e irrefutável.

A "verdade histórica", por sua vez, vai um pouco além da noção de "verdade" por si só. Ao 


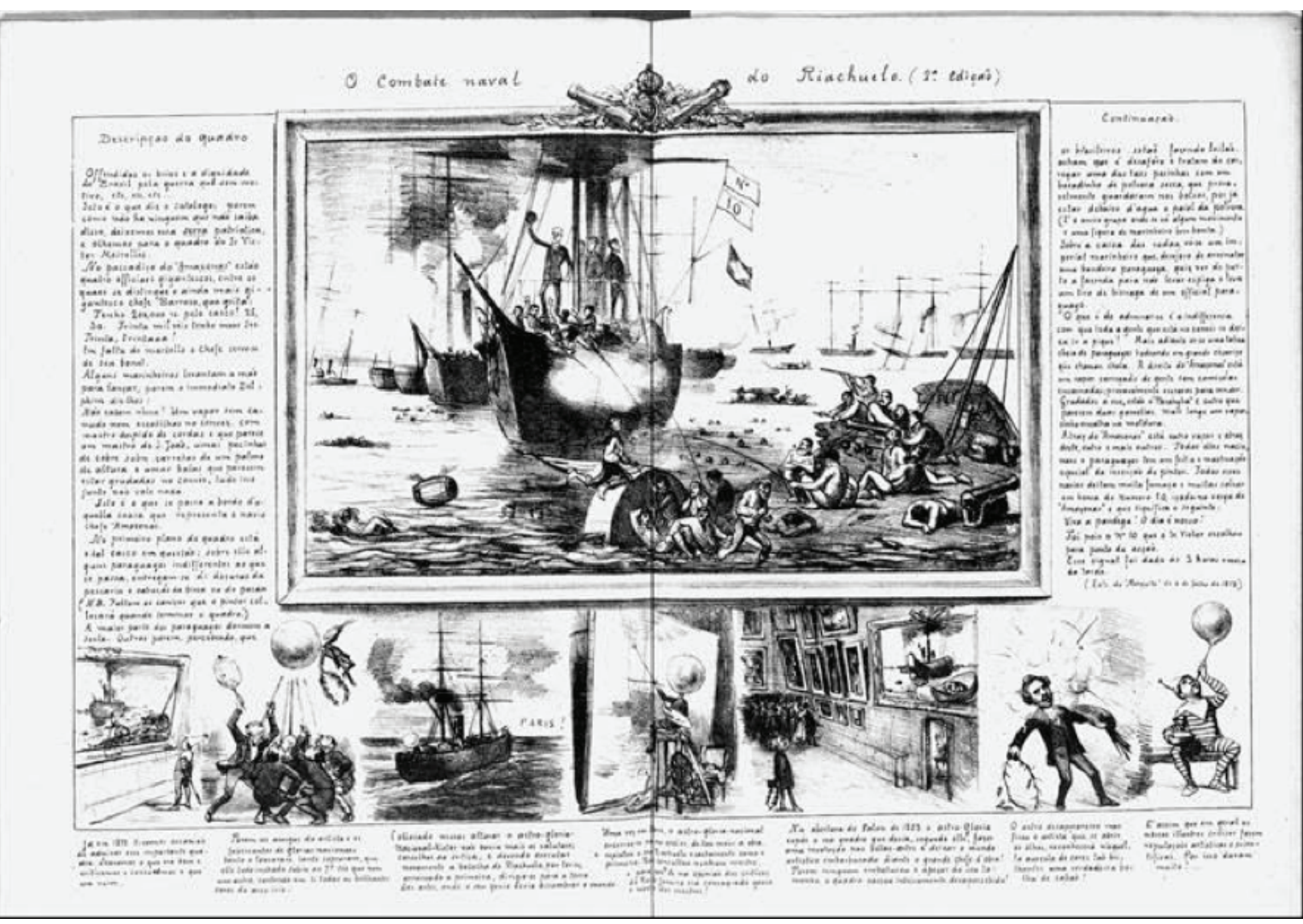

[Figura 1] Revista Illusrada. Rio de Janeiro: 1883, n. ${ }^{\circ} 363$, p. 4-5

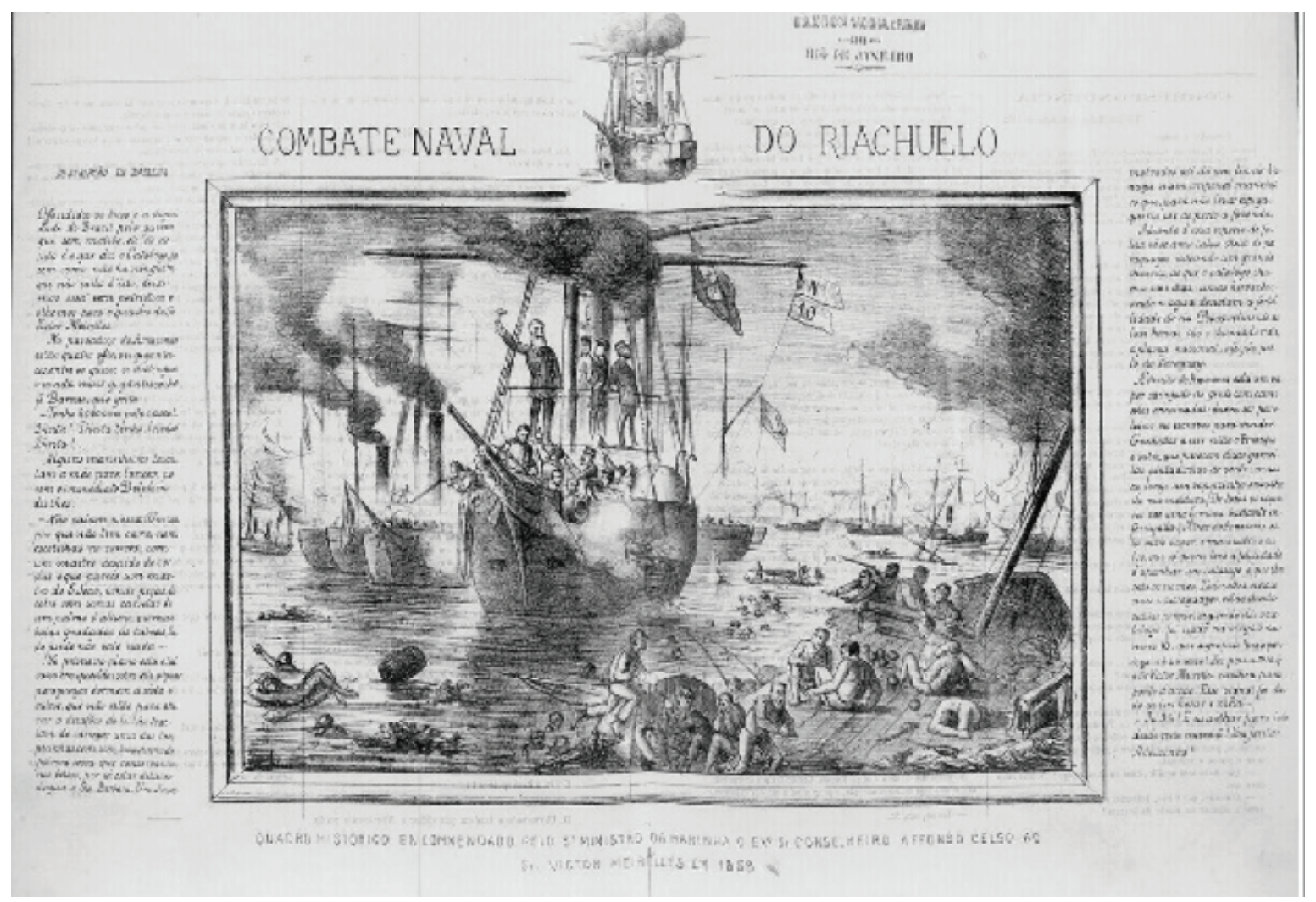

[Figura 2] O Mosquito. Rio de Janeiro: 1872, n. ${ }^{\circ} 147$, p.4-5 


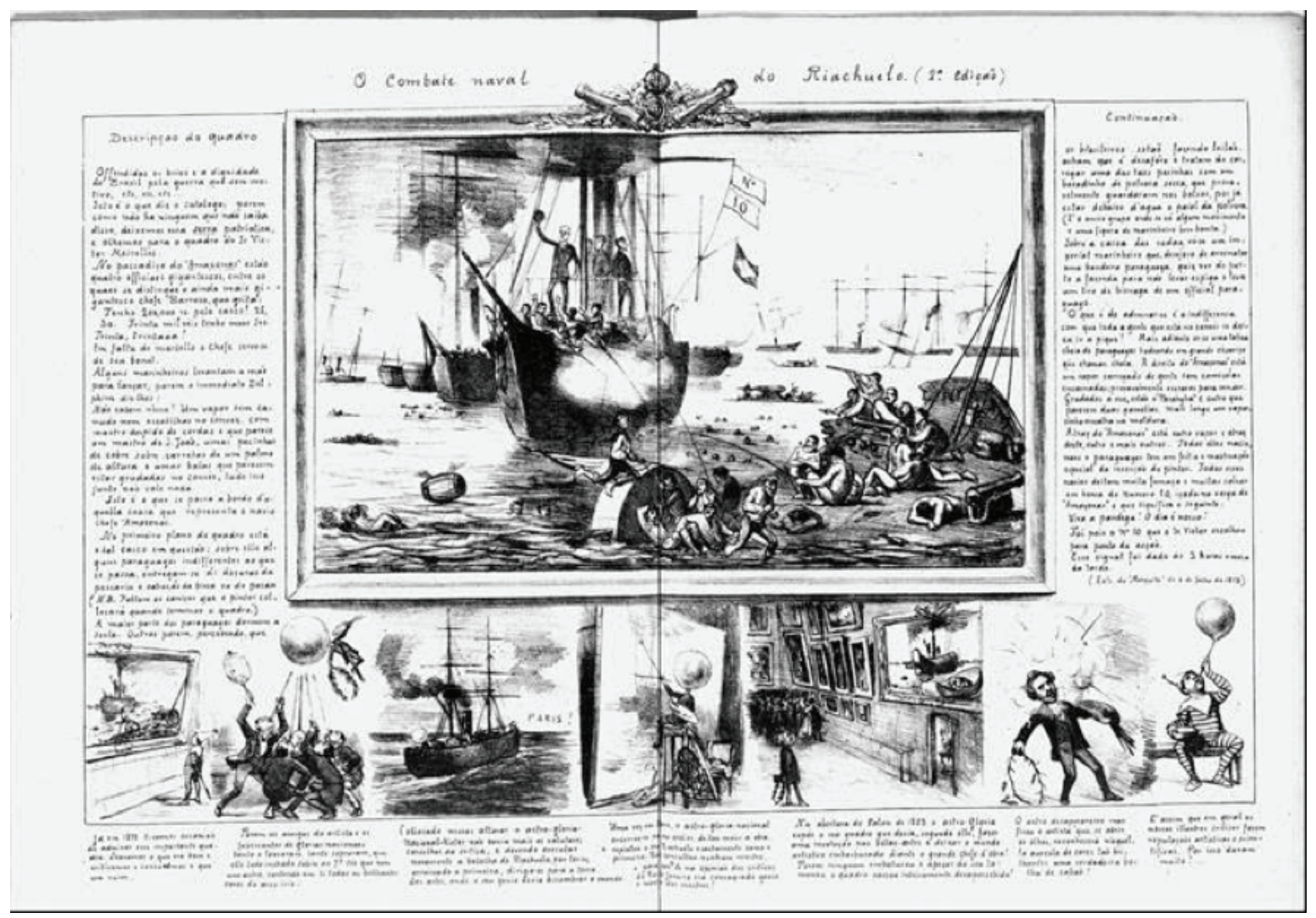

[Figura 3] Revista Illusrada. Rio de Janeiro: 1883, n. ${ }^{\circ} 363$, p. 4-5

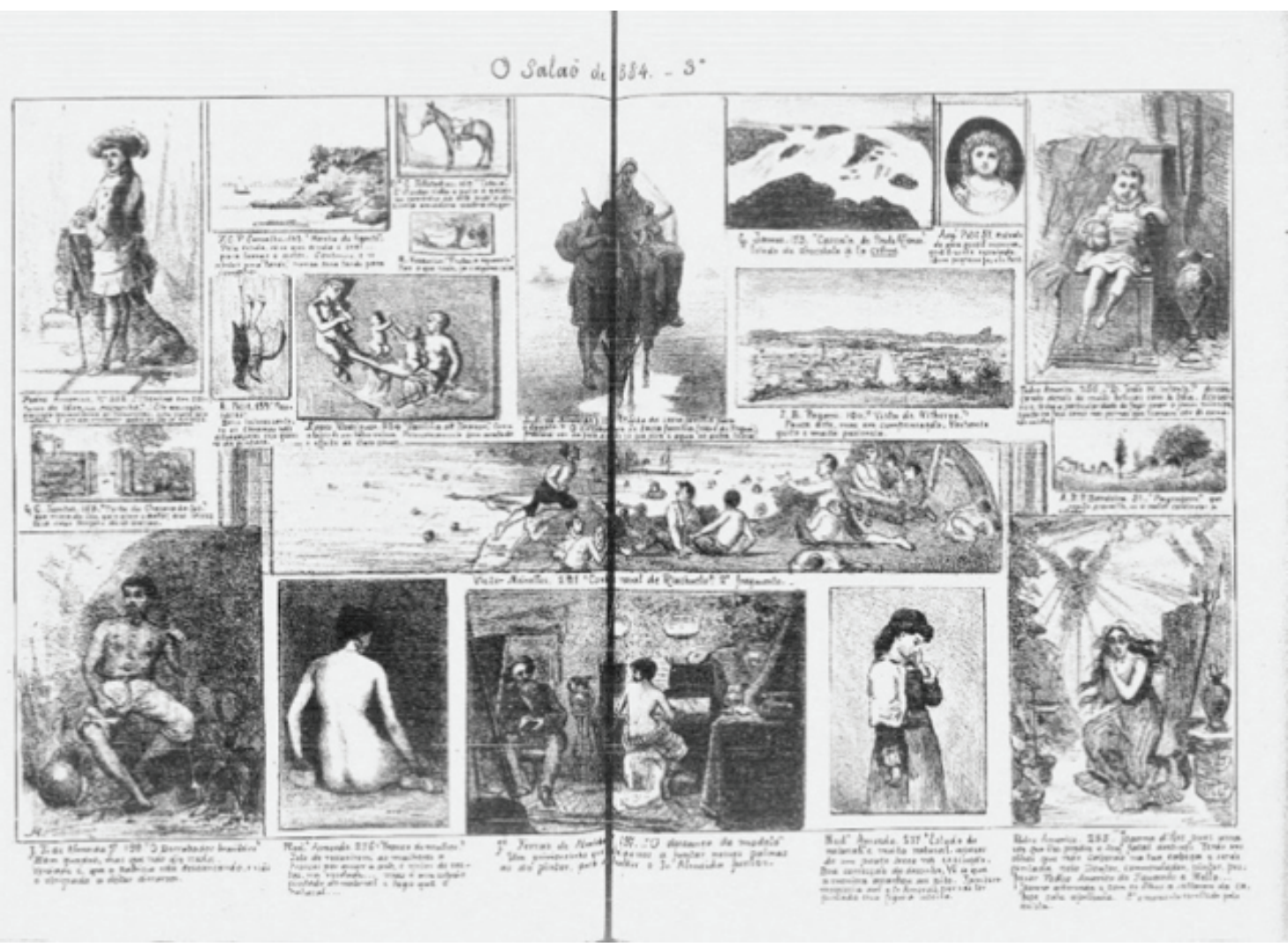

[Figura 4] Revista Illustrada, Rio de ]aneiro: 1884, n. ${ }^{\circ} 392$, p. 4-5 
criticar os quadros de batalha, a noção de verdade histórica surge como um dos parâmetros principais da crítica. Assim, quando se aponta a desproporcionalidade do Almirante Barroso na cena de Meireles, ou mesmo a composição do grupo de paraguaios, o argumento principal que se retoma é o da ausência de uma verdade histórica: o acontecimento não foi daquele jeito. Esse elemento é interessante na medida em que entra em conflito com os objetivos do artista e seus estilos, sobre sua própria consideração e concepção do que havia sido a batalha.

Duas outras noções que estão no cerne da retórica crítica ao quadro é a noção de progresso e civilização. Seguindo a ideia de que o periódico somente apresentava verdades - não interpretações, mas verdades e opiniões justas -, se fala também em como seu intuito é o de que se faça progredir as artes do país e o gosto do público. Somente dessa maneira se atingiria novos patamares de progresso e civilização.

Minha ideia aqui não é comprovar se os autores das críticas a Meireles no periódico acreditavam de fato no que estavam falando, mas sim de apresentar esses elementos que compunham os discursos referentes à crítica de arte e que, ao mesmo tempo, estavam intensamente ligados à produção dos salões caricaturais. Todos esses discursos se aliam na construção visual de uma crítica que se pretende ancorada na verdade e, sobretudo, que tem como objetivo o progresso através do aprimoramento do olhar de seu público.

Por último, gostaria de apresentar então as outras duas versões dos salões caricaturais sobre o Riachuelo, todos produzidos por Angelo Agostini. A primeira versão data de 1872, primeira vez em que o quadro foi apresentado por Meireles na Exposição de Belas Artes. É no mesmo ano que a primeira versão do salão caricatural (Imagem 2) é apresentada, então no periódico O Mosquito, no qual Angelo Agostini trabalhava. O quadro foi extremamente danificado ao retornar da Exposição Universal da Filadélfia em 1876. Em 1883, no entanto, Meireles apresentaria a segunda versão de seu quadro, idêntica à primeira, no Salon de Paris. É a partir dessa segunda versão que, em 1883, se reapresenta ao público leitor o salão caricatural de 1872, dessa vez na Revista Illustrada de Agostini (Imagem 3). Em 1884, com a Exposição Ceral de Belas Artes no Rio de Janeiro, o periódico inova: apresenta o Riachuelo por fragmentos (Imagem 4). Em cada edição, uma nova parte do quadro é exposta, de maneira que o quadro não possui mais o mesmo destaque no periódico.

Sobre essas versões, gostaria somente de fazer alguns comentários. Em primeiro lugar, podemos perceber que apesar de parecidas, existem diferenças entre as versões de 1872 e 1883. Seja por alguns detalhes ou pelo conjunto visual que forma, é possível perceber mudanças. Talvez por questões de técnica, talvez por questões de mudança no próprio quadro de Meireles, o fato é que 
algumas perguntas podem ser feitas à essas duas caricaturas. Mas, sobretudo, uma mudança é fundamental: a adição de uma sequência narrativa, que critica Meireles particularmente. O artista é extremamente desmerecido, colocado como extremamente orgulhoso e egocêntrico pela repetição de um quadro que já havia sido intensamente criticado. Aqui, destaco a mudança do discurso entre 1872 e 1883. Se antes a persona do artista era criticada muito levemente, sem ataques diretos a sua personalidade, em 1883 ele se torna alvo direto da crítica de arte. Um episódio que deve ser considerado para essa mudança é o da questão de $1879^{6}$, em que a crítica à personalidade do artista e a polarização entre os defensores de Meireles e de Pedro Américo se intensificam muito. Existe, portanto, uma mudança no discurso. $\mathrm{O}$ artista passa a ser também um elemento de desqualificação de sua própria obra. Se já o era antes, não era apontado dessa maneira pelos salões caricaturais.

Finalizo minha fala dizendo, portanto, que inúmeros elementos podem ser considerados na análise dos salões caricaturais de Agostini e da Revista Illustrada. Sua atuação em diversos âmbitos da sociedade, usando sua pena e seus comentários afiados sobre a política, os costumes e as artes, são todas potencialidades para serem consideradas em conjunto com a crítica de arte ilustrada. Aqui, busquei me atentar a alguns dos pressupostos do discurso e de que maneira eles se atrelam também à imagem, em uma dinâmica próprias das revistas ilustradas. Assim, procurei compreender as diferentes camadas da composição dos salões caricaturais de Agostini, apontando somente alguns dos elementos que considero importantes para sua compreensão.

\footnotetext{
6 A dissertação de Hugo Xavier Guarilha apresenta um levantamento muito importante sobre a polarização do debate em torno dos dois quadros de batalha produzidos por Américo e Meireles, e é possível perceber como a personalidade dos artistas se torna também um alvo da crítica ou mesmo um argumento para ela. (CF. GUARILHA, Hugo Xavier. A questão artística de 1879: Um episódio da crítica de arte no Segundo Reinado. Dissertação (Mestrado em História). 2005. IFCH-UNICAMP, Campinas-SP.)
} 


\section{Referências Bibliográficas}

AUCUSTO, José Carlos. Um provinciano na corte: as aventuras de "Nhom-Quim" e a sociedade do Rio de Janeiro nos anos 18601870. Dissertação (Mestrado em História). 2008. FFLCH-USP, São Paulo.

ARAÚJO, Aline Praxedes de. Há tantas formas de se ver o mesmo quadro: uma leitura de O Combate Naval do Riachuelo de Victor Meirelles (1872/1883). 2015. Dissertação (Mestrado em História). CCHL-UFPB, João Pessoa-PB

BALABAN, Marcelo. Poeta do lápis: sátira e política na trajetória de Angelo Agostini no Brasil Imperial (1864-1888). Campinas, SP: Editora da Unicamp, 2009.

BAXANDALL, Michael. Padrões de intenção: a explicação histórica dos quadros. São Paulo: Companhia das Letras, 2006.

CHRISTO, Maraliz de Castro Vieira. Quando subordinados roubam a cena: "A Batalha de Campo Grande" de Pedro Américo. In: Revista Seculum, n.19, João Pessoa-PB, jul./dez. 2008, p. 81-101.

COELHO, Mário César. Os panoramas perdidos de Victor Meirelles: aventuras de um pintor acadêmico nos caminhos da modernidade. Tese (Doutorado em História Cultural). Universidade Federal de Santa Catarina. Florianópolis-SC, 2007

GUARILHA, Hugo Xavier. A questão artística de 1879: Um episódio da crítica de arte no Segundo Reinado. Dissertação (Mestrado em História). 2005. IFCH-UNICAMP, Campinas-SP.

IPANEMA, Rogéria Moreira de. Arte da Imagem Impressa: a construção da ordem autoral e a gravura no Brasil do século XIX. Tese (Doutorado em História Social). Universidade Federal Fluminense, Niterói- R], 2007

MARINCONI, Gilberto. Angelo Agostini: A Imprensa Illustrada da Corte à Capital Federal: 1864-1910. São Paulo: Devir Livraria, 2011.

SILVA, Rosângela de Jesus. O Brasil de Angelo Agostini: política e sociedade nas imagens de um artista. Tese (Doutorado em História). 2010. IFCH-UNICAMP, Campinas-SP. 